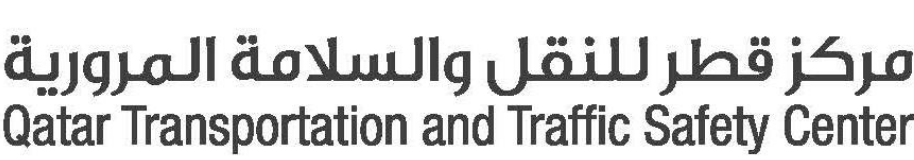

Faculty and Post Doc,

Information and Communication Technologies (ICT)

\title{
Impact of Attention Deficit Hyperactivity Disorder on Driving among Drivers in Qatar
}

Wael Alhajyaseen, Chantal Timmermans, Abdrabo Soliman, Tom Brijs, Khaled Bedair, Veerle Ross,

\section{Wondwesen Mamo}

\section{Problem statement}

* Attention Deficit Hyperactivity Disorder (ADHD) defined in inattention and hyperactivity-impulsivity,

- ADHD can affect a day-to-day activities of a person, including driving competency

- Driving is a complex action that demands on perceptual, cognitive, and motor processes.

- ADHD involves deficiencies that affect those important aspects in driving performance.

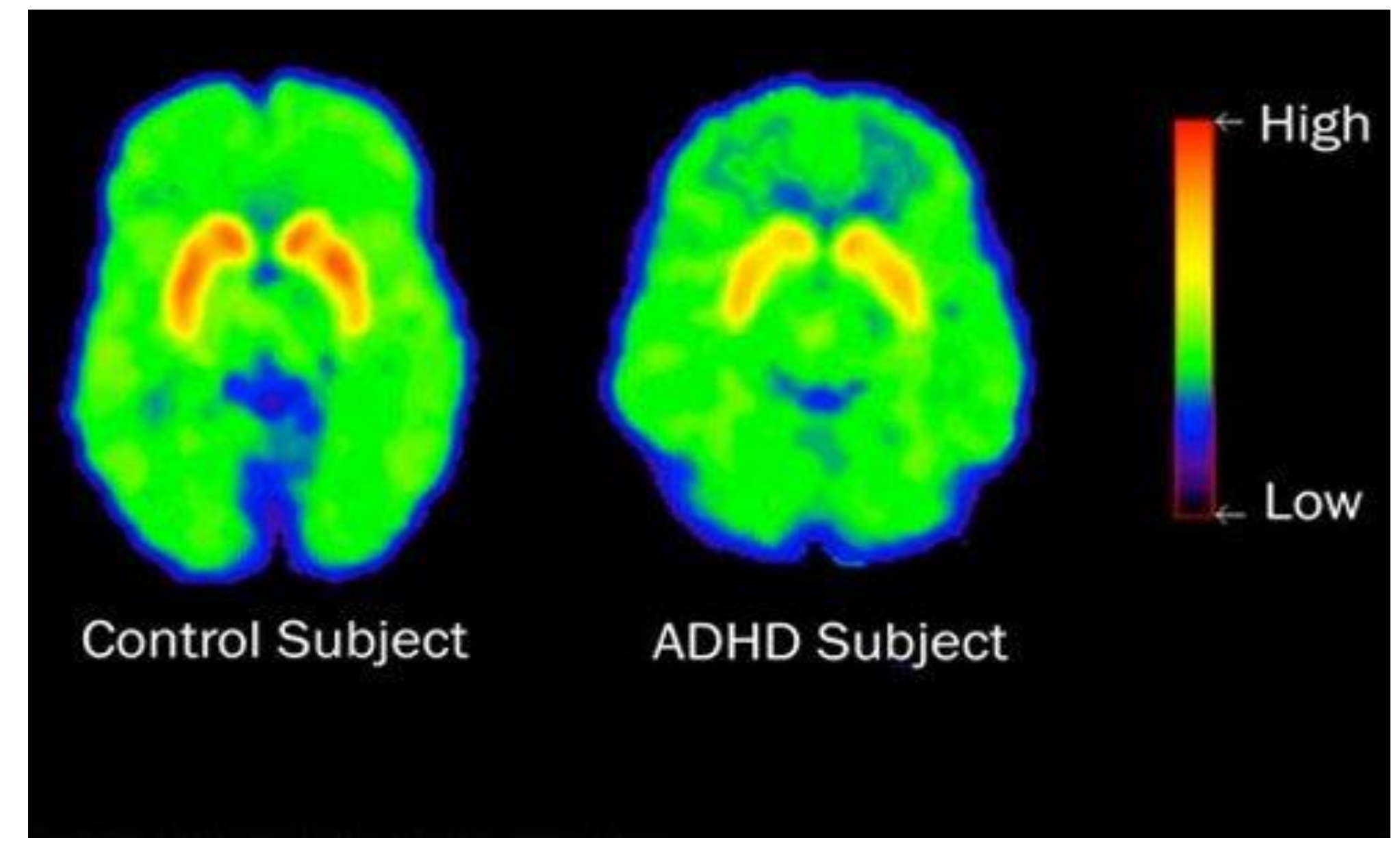

levels of dopamine transporters

Source:

htrns//cab-use1 wpmuch com/sites dartmouth edu/dist/2/2024/files/2009/11/adhd cmuki

\section{Objectives}

* To investigate the influence of the hyperactivityimpulsivity trait on Deviant Driving Behaviors (DDB) * To examine the effect of the inattention trait on DDBs

* To determine whether these effects are similar for male drivers in comparison to female drivers.

\section{Conclusions}

\section{Male drivers}

* Hyperactivity-impulsivity trait predominantly predicts DDBs

- Inattention brings a significant but minor effect on ordinary violations, errors \& lapses.

\section{Female drivers}

- Inattention has a dominating role in comparison to the hyperactivity-impulsivity trait. - Aggressive violations are predicted by the inattention trait

- Aggressive violations are not predicted by the hyperactivity-impulsivity trait

- It was observed a significant positive relation between the inattention trait with DDBs.

\section{Male-Female Drivers}

- Relationship between inattention trait and aggressive violations is found for female - This relationship is not found for the male

- Co-morbid to ADHD need to be considered for gender related to aggressive violations

\section{Recommendations}

* Develop driving training and education programs

- Create an inclusion of drivers with a mental diagnosis in driving school

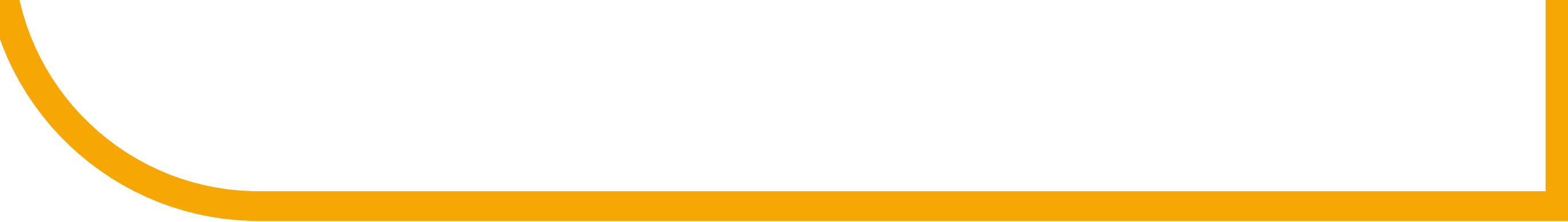

\section{METHODOLOGY}

\section{Data Collection Tool}

1. The adult ADHD self-report scale (ASRS-V1.1)

* 5 point scale: never (0) to very often (4)

* 18 self-administered questions

* Measure inattention \& hyperactivity-impulsivity

\section{The Driver Behaviour Questionnaire (DBQ)}

* 6 points scale: never (1) to nearly all the time (6).

* 27 items to measures DDBs

* DDBs include errors, ordinary violations,

aggressive violations \& lapses

8 items for each of DDBs except aggressive

violations

* Three items to measure aggressive violations

\section{Statistical analysis}

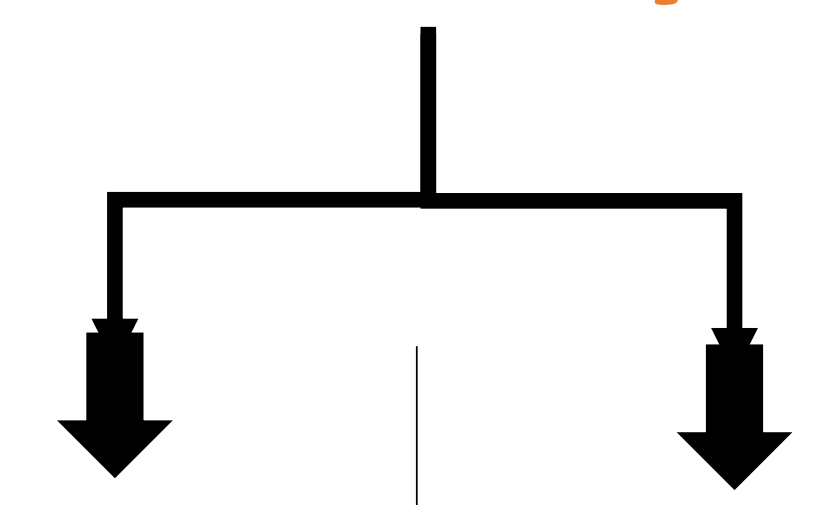

Descriptive statistics Path analysis model

\section{Participants}

450 drivers

* Age range 18 - 30 years old

Driving experience range $1-13$ years
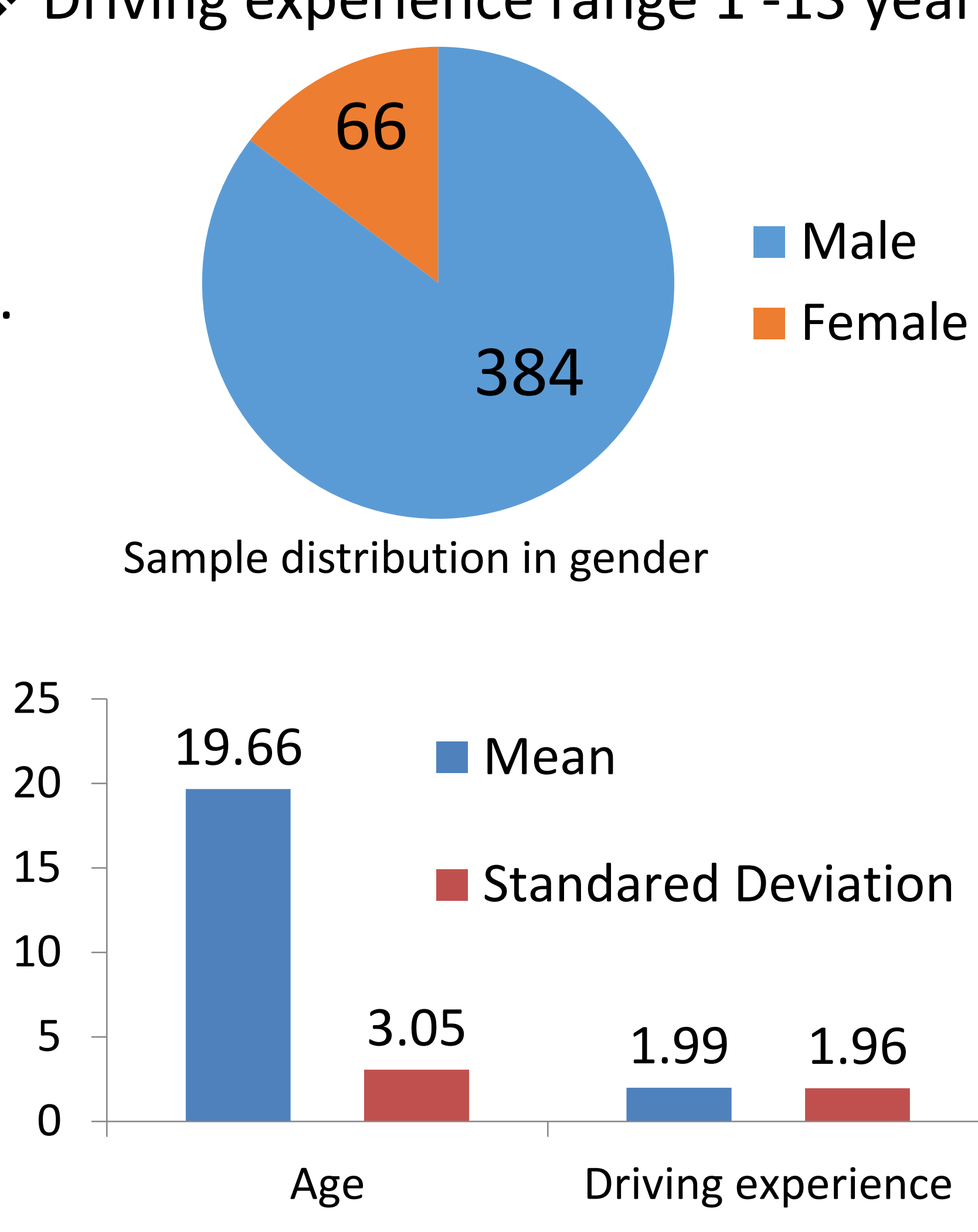

Mean \& Standard Deviation scores for age \& driving experience of participants

\section{CONCLUSION}

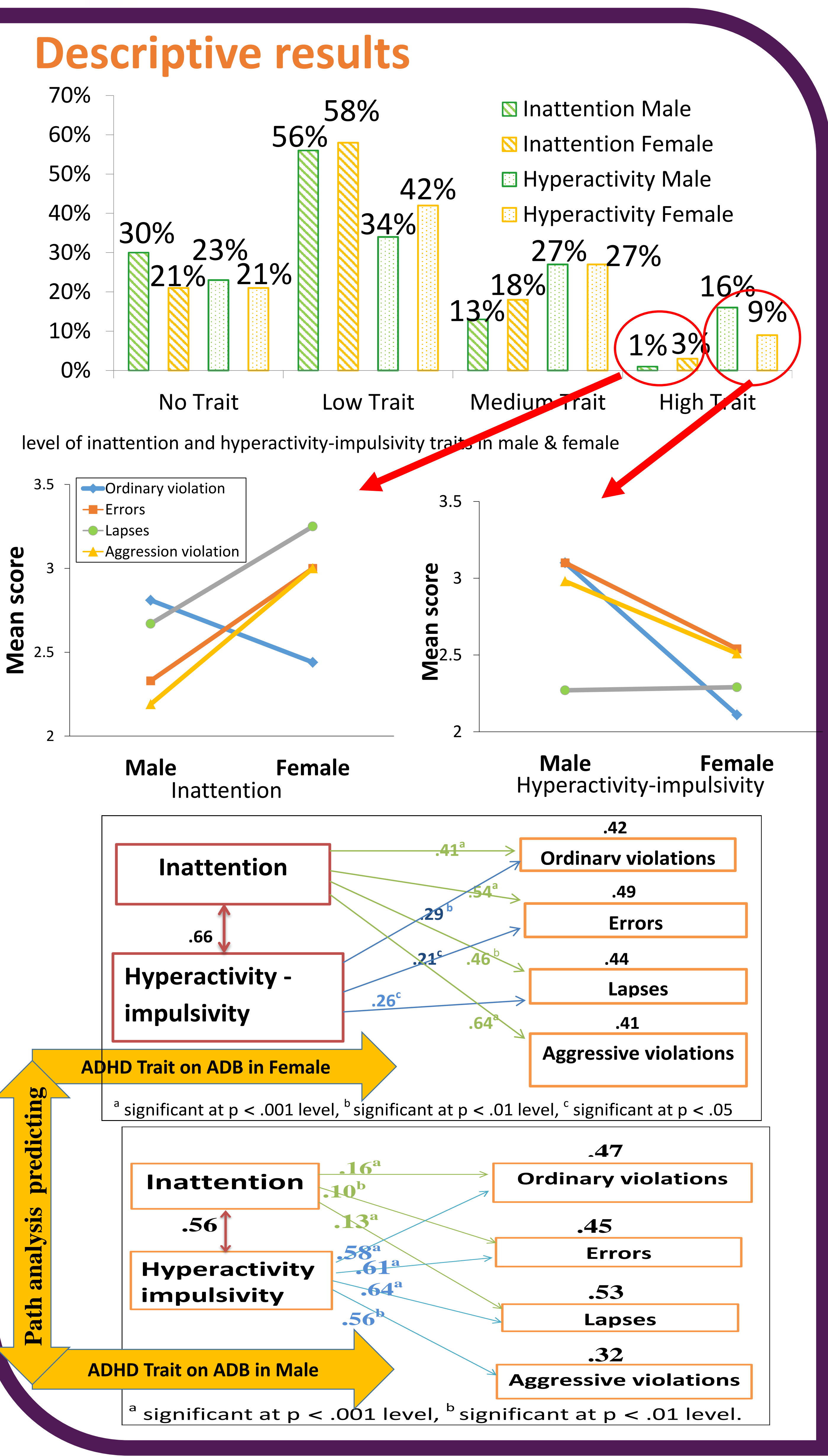

